\title{
Ambient luminance and vertical migration of the sardine Sardina pilchardus
}

\author{
M. Giannoulaki ${ }^{1}$, A. Machias ${ }^{2, *}$, N. Tsimenides ${ }^{1}$ \\ ${ }^{1}$ University of Crete, Department of Biology, PO Box 1470, GR-71110 Iraklion, Crete, Greece \\ ${ }^{2}$ Institute of Marine Biology of Crete, PO Box 2214, GR-71003, Iraklion, Crete, Greece
}

\begin{abstract}
The vertical migration of the sardine Sardina pilchardus W. was investigated in terms of a dynamic movement in the wild. The hourly position of the centre of sardine density (the weighted mean depth of sardines in the water column) was estimated by means of a dual beam echosounder during the daytime. The luminance profile of the water column was measured hourly over an extended network of 154 stations. The diel patterns of the vertical movements of the sardines were examined in relation to surface light intensity, bottom depth and ambient light intensity changes at the depth they occupied. Light intensity and bottom depth were found to affect the sardine movements. The centre of sardine density tended to level out as the light intensity increased and a wide range of 'preferred' light intensities was observed. An abrupt descending and ascending took place at dawn and dusk, respectively, whereas in the intermediate hours the depth of the sardines was rather constant. The importance of background light intensity seemed to be greater than measured light intensity. The field measurements were fitted to a cosine model to describe the pattern of diel movements.
\end{abstract}

KEY WORDS: Sardina pilchardus · Vertical migrations · Light intensity

\section{INTRODUCTION}

The diel vertical migration of clupeids towards the surface at dusk, when the schools disperse, and towards the seabed at dawn, when the schools reform, is well known (Woodhead 1966, Blaxter \& Hunter 1982). Earlier investigations led to the conclusion that light played a major role in initiating these vertical migrations (Woodhead 1966, Blaxter 1970). Furthermore, light seemed to be the main stimulus that governed or influenced behaviour related to these movements, such as feeding, schooling and spawning (Blaxter \& Parrish 1965, Woodhead 1966). Extensive surveys of vertical migration of marine organisms took place after the second World War as a result of the introduction and wide use of echosounders (Blaxter \& Hunter 1982). Use of echosounders to plot the movements of schools helped to clarify the relationship between these move-

\footnotetext{
- Addressee for correspondence.

E-mail: amachias@talos.cc.uch.gr

ments and the environment (Arnold 1995). A number of investigations have shown that the amplitude of such movements depends on the physiological state (e.g. maturity) and age of the migrating fish, as well as on the presence of temperature gradients, specific hydrographic conditions and predators (Woodhead 1966, Blaxter \& Hunter 1982). The importance of vertical migrations has been discussed extensively because they affect fisheries (Woodhead 1966, Blaxter 1970 , Blaxter \& Hunter 1982), as well as the estimation of fish abundance by means of echosounders. The latter effect is due to changes in the target strength, as a result of changes in the depth at which physostomous fishes are insonified (MacLennan \& Simmonds 1992).

There is a great deal of information about the vertical migrations of several species. Numerous laboratory experiments have dealt with the reactions of fishes to light. Considerable research has been focused on herring. Schools of herring break up at light intensity $<0.1 \mathrm{mc}$ (metre candle) and are re-established at 0.1 to $10 \mathrm{mc}$, while herring threshold for feeding is $<0.1 \mathrm{mc}$ (Table 1 ). Our knowledge concerning the sardine Sardina pil- 
Table 1. Light intensity thresholds (in mc) of different clupeid species. PLI: preferred light intensity

\begin{tabular}{|c|c|c|c|c|c|}
\hline Species & $\begin{array}{l}\text { Break up of } \\
\text { schools }(\mathrm{mc})\end{array}$ & $\begin{array}{l}\text { Reestablishment } \\
\text { of schools (mc) }\end{array}$ & $\begin{array}{l}\text { Luminance threshold } \\
\text { of feeding }(\mathrm{mc})\end{array}$ & $\begin{array}{l}\text { PLI } \\
(\mathrm{mc})\end{array}$ & Source \\
\hline Sardina pilchardus & & 0.5 & $<0.2-10$ & & Muzinic $(1963,1964)$ \\
\hline Sardina pilchardus ${ }^{a}$ & & $0.06-0.5$ & & $25-100$ & Cushing $(1960)$ \\
\hline Clupea harengus & & & $\begin{array}{c}<0.007 \text { feeding singly } \\
<0.036 \text { feeding as a group }\end{array}$ & & Blaxter (1964) \\
\hline Clupea harengus & & & $<0.01$ & & Blaxter (1966) \\
\hline Clupea harengus & & & $<0.1-10$ & & Blaxter (1980) \\
\hline Clupea harengus & & & $<0.001-0.01$ & & Batty et al. (1990) \\
\hline Clupea harengus & & $0.06-0.5$ & $0.036-0.007$ & & $\begin{array}{l}\text { Blaxter (1964), Blaxter \& } \\
\text { Parrish (1965) }\end{array}$ \\
\hline Clupea harengus ${ }^{\mathrm{a}}$ & & & 0.25 & & Blaxter \& Holiday (1958) \\
\hline Clupea harengus & $\begin{array}{c}0.1-0.05 \text { (May) } \\
0.5-0.01 \text { (June) } \\
0.1-0.05 \text { (July) }\end{array}$ & $\begin{array}{l}0.1-50 \text { (May) } \\
0.1-10 \text { (June) } \\
0.1-10 \text { (July) }\end{array}$ & & $10-1000$ & Blaxter \& Parrish (1965) \\
\hline Engraulis encrasicolus & $0.1-10$ & & & & Blaxter (1970) \\
\hline
\end{tabular}

chardus W. is more limited, despite the commercial importance of this fish, especially in the Mediterranean Sea (Stergiou 1989). Sardines schools are re-established at a light intensity $0.5 \mathrm{mc}$, while the threshold for feeding is $<0.2 \mathrm{mc}$ (Table 1). In spite of the importance of light, field data that directly correlate specific light intensities with fish displacement are limited (Blaxter \& Parrish 1965). There are no data available on how light affects the sardine's vertical migration movements in the wild. The vertical migrations of this fish have not been examined as a dynamic reaction to ambient light intensity. The available field data usually correlate vertical migration with time of day (Cushing 1960, Woodhead 1966. Culley 1970) and not with the ambient light intensity.

The aim of the present study is to investigate the relationship between light intensity and the vertical migration of sardines in the wild, by means of hydroacoustic and ambient light intensity measurements. The vertical migration of fish in relation to light was examined in situ in terms of a dynamic process. A standard model of movement, in relation to time of day, was constructed for each sub-area of the northern Aegean Sea, in summer. The sardines' diel movements were examined in relation to ambient light intensity, changes in ambient light intensity, bottom depth and auto-correlation factors.

\section{MATERIALS AND METHODS}

Sampling procedure. Data were collected during 2 hydroacoustic surveys in the Thermaikos Gulf in June 1995 and 1996 and in the Thracian Sea in June 1996
(Fig. 1). The speed of the vessel was 8 nautical miles ( $\mathrm{n}$ mile) per hour (Tsimenides et al. 1995). The acoustic system used was a $120 \mathrm{kHz}$ dual-beam echosounder (Biosonics). The echoes were analysed using the software ESP V21 (Biosonics 1992). The light intensity profiles of the water column were measured every $5 \mathrm{n}$ miles, using a Quantum Scalar Profiling Sensor (QSP200PD) which was attached to a SEA-BIRD CTD unit.

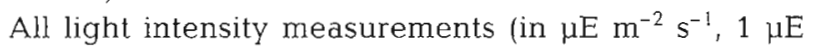
$\mathrm{m}^{-2} \mathrm{~s}^{-1}=51.2 \mathrm{mc}$ ) referred to light wavelengths in the range of 400 and $700 \mathrm{~nm}$ (the photosynthetically active radiation) and were transformed to candles on $1 \mathrm{~m}^{2}$ (mc) for comparison with other studies. Over the course of the 154 stations, the light intensity profile of the water column was obtained every hour. The measurements of the light intensity at each station were averaged every $10 \mathrm{~m}$ and the resulting values were assigned to the depth of the midpoint in each depth interval. The mean bottom depth was also estimated hourly by averaging all the measurements of the echosounder over $1 \mathrm{~h}$.

Acoustic echoes were registered continuously along the transects and were integrated over each hour, serving as 1 sampling unit. The main species in the area were Sardina pilchardus, Engraulis encrasicholus, Trachurus sp. and Sardinella aurita (Stergiou 1989). The sardine echoes were discriminated from those of other fishes by the characteristic echogram shape, size and back-scattered energy of their schools between 04:00 to $22: 00 \mathrm{~h}$. All unidentified schools ( $8 \%$ of the total echo) have been excluded from the analysis. The main species that could be mistakenly identified as sardine was Sardinella aurita during the period of school 


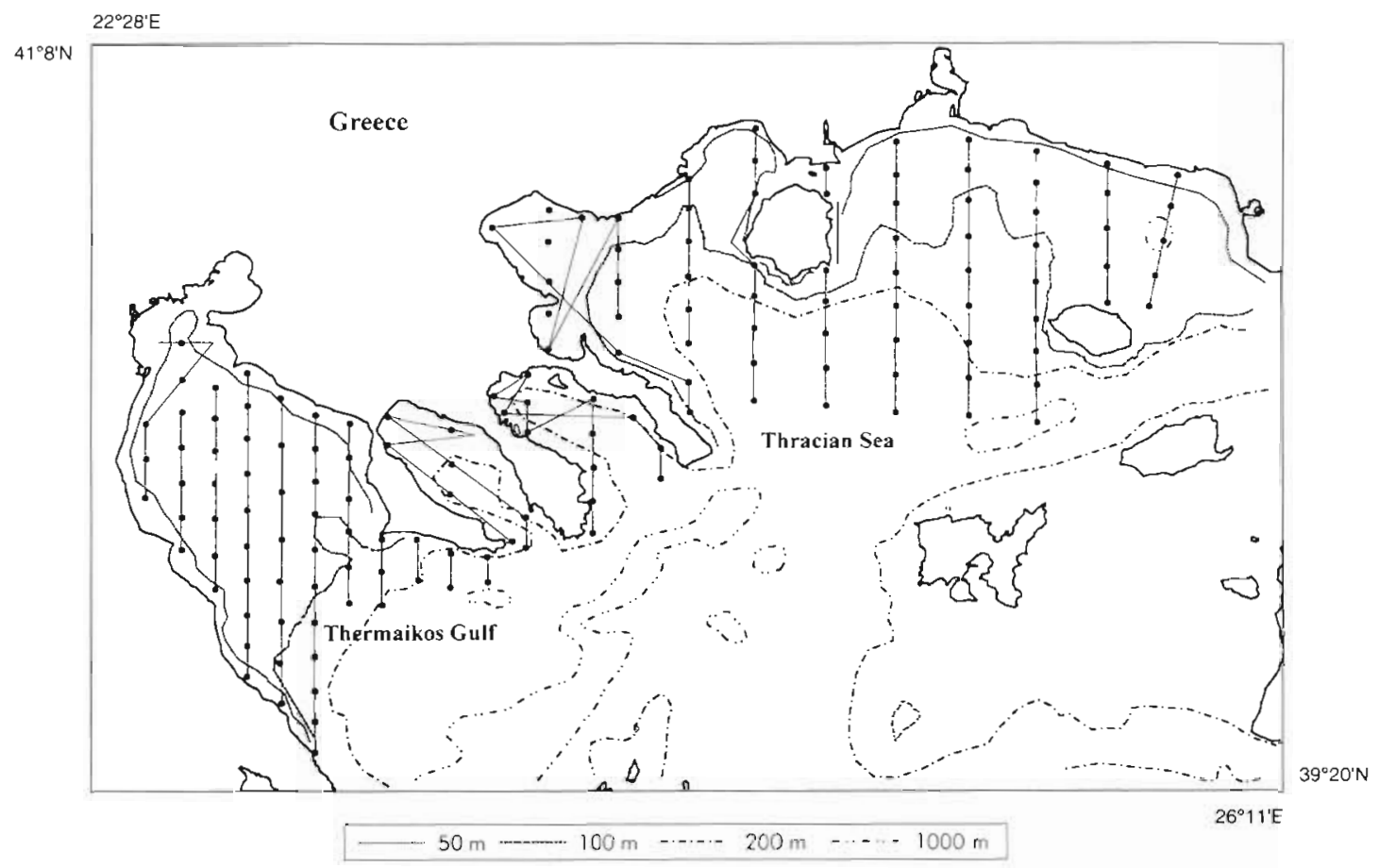

Fig. 1. Study area in the northern Aegean Sea during the research survey of 1996. Transects and the CTD stations are indicated

reforming ( $6 \%$ of the total echo). Since during this period all species remain approximately at the same mean depth, no significant bias was introduced due to mistaken identification. Information on fish schools was obtained by means of 10 identification hauls in 1995 and 28 in 1996 (Table 2). A pelagic trawl with a 10 $\mathrm{mm}$ cod-end and a vertical opening of $20 \mathrm{~m}$ was used in both surveys. A netsonde (Furuno CN-21) was attached to the headline of the net to identify the specific schools fished. Trawling was carried out at a speed of 3 to 4 knots.

The vertical distribution of the sardine was determined hourly by integration of sardine acoustic backscattering strength for every $10 \mathrm{~m}$ depth interval, from $5 \mathrm{~m}$ below the surface down to $95 \mathrm{~m}$. For each sampling unit the weighted mean depth (WMD, or the centre of sardine density) was determined. The WMD of the sardine was calculated by weighting each depth with the corresponding concentration of fish (Heath et al. 1988):

$$
\text { WMD }=\frac{\sum_{i=1}^{n} s_{i} \cdot D_{i}}{\sum_{i=1}^{n} s_{i}}
$$

where $s_{i}=$ the sardine integrated acoustic cross section at depth $i$ and $D_{1}=$ depth of fish in the water column, $\mathrm{n}=$ number of depth intervals. The WMD was assigned to the mid-point of an hour and was considered as the value of each sampling unit. The light intensity at the
WMD (LIMD) was determined from the corresponding measurements in the water column.

Data analysis. The analysis was performed for each of 2 sub-areas: the Thermaikos Gulf and the Thracian Sea, which have different bottom depths. Specifically, in the Thermaikos Gulf, bottom depths $<100 \mathrm{~m}$ predominate, whereas in the Thracian Sea bottom depths $>100 \mathrm{~m}$ are common. In each sub-area, cross-correlation analysis was used to determine and compare the periodicity and phase differences of variations in WMD and the mean light intensity in the first $10 \mathrm{~m}$ (LI) in the water column (Heath et al. 1988). The results of crosscorrelation analysis were used to estimate the lag in the fish response to light changes. Furthermore, stepwise multiple regression analysis (Wonnacott \& Wonnacott 1981) was performed to examine the influence of light and bottom depth on the vertical movement of sardines. The Durbin-Watson test was used to check autocorrelation in regression models. Durbin-Watson tests the hypothesis of no autoregression $(r=0)$ against the hypothesis $r>0$, where $r$ is the coefficient of correlation between errors $\varepsilon_{t}$ and $\varepsilon_{t-1}$. Test values lower than 2 at a significance level of 0.05 indicated positive autocorrelation (Kmenta 1986).

The WMD values were further analysed by means of time-series techniques. The residuals of multiple regression analysis were used to produce a stationary time series. We used the Box-Jenkins ARIMA model process of order $(p, d, q)$, which has the general expression: ARIMA $(p, d, q):\left(1-\varphi_{1} B-\varphi_{1} B^{2}-\ldots\right.$ 
Table 2. Catch composition of the hauls. Depth: mean depth of the haul; Time: starting time of the hauli Lat: starting latitude of the haul; Long: starting longitude of the haul; Other: the percentages of the haul catch for each species; Total catch: the total catch in $g$

\begin{tabular}{|c|c|c|c|c|c|c|c|c|}
\hline $\begin{array}{l}\text { Depth } \\
\text { (m) }\end{array}$ & $\begin{array}{l}\text { Time } \\
\text { (h) }\end{array}$ & $\begin{array}{l}\text { Lat } \\
\text { (N) }\end{array}$ & $\begin{array}{l}\text { Long } \\
\text { (E) }\end{array}$ & $\begin{array}{c}\text { Sardina } \\
\text { pilchardus }\end{array}$ & $\begin{array}{c}\text { Engraulis } \\
\text { encrasicholus }\end{array}$ & Trachurus sp. & Other & $\begin{array}{l}\text { Total } \\
\text { catch }\end{array}$ \\
\hline \multicolumn{9}{|l|}{1995} \\
\hline 50.5 & $09: 19$ & $40^{\circ} 01^{\prime}$ & $23^{\circ} 15.5^{\prime}$ & 56.25 & 28.13 & 15.63 & 0.00 & 3200 \\
\hline 43 & $23: 00$ & $40^{\circ} 13.5^{\prime}$ & $23^{\circ} 10.3^{\prime}$ & 75.99 & 11.86 & 11.02 & 1.13 & 3540 \\
\hline 53.5 & $10: 38$ & $39^{\circ} 43.8^{\prime}$ & $23^{\circ} 04.3^{\prime}$ & 2.25 & 80.90 & 16.85 & 0.00 & 1890 \\
\hline 40 & $08: 45$ & $40^{\circ} 17.9^{\prime}$ & $22^{\circ} 55.7$ & 93.11 & 0.00 & 6.89 & 0.00 & 5370 \\
\hline 25 & $21: 00$ & $40^{\circ} 15.6^{\prime}$ & $22^{\circ} 58.6^{\prime}$ & 96.63 & 2.63 & 0.74 & 0.00 & 12160 \\
\hline 25 & $23: 00$ & $40^{\circ} 15.5^{\prime}$ & $23^{\circ} 06^{\prime}$ & 8.02 & 60.96 & 31.02 & 0.00 & 9350 \\
\hline 25 & $04: 59$ & $40^{\circ} 11.5^{\prime}$ & $23^{\circ} 04.7^{\prime}$ & 12.22 & 77.98 & 6.25 & 3.55 & 7040 \\
\hline 30 & $03: 59$ & $40^{\circ} 12.5^{\prime}$ & $23^{\circ} 10^{\prime}$ & 9.41 & 85.49 & 5.10 & 0.00 & 2550 \\
\hline 44 & $18: 35$ & $39^{\circ} 55.6^{\prime}$ & $22^{\circ} 50.7^{\prime}$ & 74.21 & 0.00 & 0.00 & 25.79 & 1539 \\
\hline 20 & $00: 09$ & $39^{\circ} 49.5^{\prime}$ & $22^{\circ} 58^{\prime}$ & 5.77 & 87.82 & 0.00 & 6.41 & 1560 \\
\hline \multicolumn{9}{|l|}{1996} \\
\hline 38 & $11: 08$ & $40^{\circ} 33.7^{\prime}$ & $25^{\circ} 27.7^{\prime}$ & 11.76 & 88.24 & 0.00 & 0.00 & 1700 \\
\hline 26.5 & $00: 02$ & $40^{\circ} 35.5^{\prime}$ & $25^{\circ} 20^{\prime}$ & 1.23 & 92.59 & 6.17 & 0.00 & 1620 \\
\hline 55 & $18: 50$ & $40^{\circ} 50.5^{\prime}$ & $25^{\circ} 19^{\prime}$ & 87.82 & 5.77 & 0.00 & 6.41 & 1560 \\
\hline 45 & $20: 04$ & $40^{\circ} 43.3^{\prime}$ & $25^{\circ} 20.1^{\prime}$ & 100.00 & 0.00 & 0.00 & 0.00 & 600 \\
\hline 19.5 & $20: 46$ & $40^{\circ} 37.4^{\prime}$ & $25^{\circ} 18.5^{\prime}$ & 0.00 & 85.00 & 15.00 & 0.00 & 400 \\
\hline 30 & $00: 20$ & $40^{\circ} 23.3^{\prime}$ & $25^{\circ} 22.9^{\prime}$ & 0.00 & 99.46 & 0.54 & 0.00 & 5550 \\
\hline 80 & $16: 29$ & $40^{\circ} 21.7^{\prime}$ & $25^{\circ} 29.1^{\prime}$ & 100.00 & 0.00 & 0.00 & 0.00 & 1800 \\
\hline 44 & $19: 35$ & $40^{\circ} 26.3^{\prime}$ & $25^{\circ} 45.5^{\prime}$ & 0.00 & 0.00 & 0.00 & 100 & 1600 \\
\hline 30 & $21: 20$ & $40^{\circ} 26.7^{\prime}$ & $25^{\circ} 47.5^{\prime}$ & 20.00 & 0.00 & 80.00 & 0.00 & 1250 \\
\hline 27 & $20: 25$ & $40^{\circ} 30.4^{\prime}$ & $25^{\circ} 26.7^{\prime}$ & 94.81 & 0.00 & 2.31 & 2.89 & 30800 \\
\hline 31.5 & $20: 37$ & $40^{\circ} 33.6^{\prime}$ & $24^{\circ} 48.3^{\prime}$ & 0.00 & 6.25 & 93.75 & 0.00 & 1160 \\
\hline 20 & $21: 00$ & $40^{\circ} 48^{\prime}$ & $24^{\circ} 33.2^{\prime}$ & 99.84 & 0.01 & 0.10 & 0.05 & 93950 \\
\hline 28 & $13: 52$ & $40^{\circ} 48.5^{\prime}$ & $24^{\circ} 24.2^{\prime}$ & 95.81 & 3.46 & 0.73 & 0.00 & 38160 \\
\hline 30 & $20: 48$ & $40^{\circ} 34.7^{\prime}$ & $23^{\circ} 59.3^{\prime}$ & 85.11 & 7.87 & 7.02 & 0.00 & 3560 \\
\hline 27 & $23: 47$ & $40^{\circ} 381^{\prime}$ & $23^{\circ} 53.6^{\prime}$ & 95.10 & 4.65 & 0.00 & 0.25 & 27550 \\
\hline 22 & $03: 35$ & $40^{\circ} 32.3^{\prime}$ & $24^{\circ} 04.9^{\prime}$ & 94.56 & 5.44 & 0.00 & 0.00 & 15060 \\
\hline 38 & $19: 13$ & $40^{\circ} 40.4^{\prime}$ & $23^{\circ} 48.9^{\prime}$ & 28.84 & 70.59 & 0.58 & 0.00 & 8670 \\
\hline 25 & $21: 37$ & $40^{\circ} 39^{\prime}$ & $23^{\circ} 57^{\prime}$ & 47.37 & 52.63 & 0.00 & 0.00 & 1380 \\
\hline 34 & $09: 16$ & $40^{\circ} 07.7^{\prime}$ & $23^{\circ} 11.9^{\prime}$ & 99.46 & 0.00 & 0.54 & 0.00 & 7460 \\
\hline 21 & $00: 08$ & $39^{\circ} 45.6^{\prime}$ & $23^{\circ} 04.2^{\prime}$ & 0.00 & 99.17 & 0.83 & 0.00 & 31200 \\
\hline 30 & $16: 19$ & $39^{\circ} 38.1^{\prime}$ & $23^{\circ} 05^{\prime}$ & 85.71 & 14.29 & 0.00 & 0.00 & 1400 \\
\hline 43 & $20: 20$ & $39^{\circ} 41^{\prime}$ & $23^{\circ} 01.1^{\prime}$ & 0.68 & 93.40 & 5.93 & 0.00 & 11810 \\
\hline 20.5 & $00: 03$ & $39^{\circ} 42.5^{\prime}$ & $22^{\circ} 58.7^{\prime}$ & 2.27 & 81.82 & 15.91 & 0.00 & 1320 \\
\hline 44 & $13: 01$ & $40^{\circ} 19.9^{\prime}$ & $22^{\circ} 56^{\prime}$ & 75.03 & 12.48 & 12.48 & 0.00 & 14820 \\
\hline 44 & $19: 15$ & $40^{\circ} 02.1^{\prime}$ & $23^{\circ} 18.6^{\prime}$ & 76.92 & 23.08 & 0.00 & 0.00 & 1300 \\
\hline 62 & $14: 13$ & $40^{\circ} 10.4^{\prime}$ & $23^{\circ} 15.8^{\prime}$ & 69.06 & 0.00 & 30.94 & 0.00 & 4170 \\
\hline 74 & $17: 23$ & $39^{\circ} 50.5^{\prime}$ & $22^{\circ} 15^{\prime}$ & 91.50 & 8.50 & 0.00 & 0.00 & 18820 \\
\hline 35 & $21: 07$ & $39^{\circ} 48.3^{\prime}$ & $22^{\circ} 55.5^{\prime}$ & 0.00 & 100.00 & 0.00 & 0.00 & 21460 \\
\hline
\end{tabular}

$\left.-\varphi_{\mathrm{p}} B^{p}\right)(1-B)^{d} Y_{1}=\left(1-\theta_{1} B-\theta_{2} B^{2}-\ldots-\theta_{q} B^{q}\right) a_{l}($ Wonnacott \& Wonnacott 1.981), where $p$ is the order of the auto-regressive parameter; $d$ is the difference order; $q$ is the order of the moving average parameters; $B$ is the back-shift operator; $B^{j} Y_{t}=Y_{1-j} ; \varphi_{1}, \varphi_{2}, \ldots$ are autoregressive parameters; $a_{t}$ is random noise at time $t_{;} \theta_{1}$, $\theta_{2}, \ldots$ are moving average parameters; and $Y_{t}$ is the observation at time $t$ (Gutierrez \& Morales-Nin 1986). After this, we performed a second stepwise multiple regression analysis to examine all the known factors that could influence sardine vertical migration patterns, e.g auto-correlation factors, light intensity and bottom depth. These factors were used as independent variables and the WMD as the dependent variable.
To examine the sardines' response to light changes more thoroughly the following calculations were performed: (1) the WMD and LIMD were averaged for every hour of the $24 \mathrm{~h}$ period in the Thracian Sea (where the bottom effect was small), (2) the mean hourly change in the light intensity $(\Delta L I)$ was estimated by subtracting the LIMD from the light intensity at the same depth $1 \mathrm{~h}$ later. The $\Delta \mathrm{LI}$ was examined in relation to changes in the WMD.

Moreover, we estimated the light intensity level at which the sardines tended to be concentrated (the 'preferred' light intensity: PLI) using LIMD values of sampling units that conformed with the following criteria: (1) measurements between 07:00 and 19:00 h 
(where no significant changes in WMD had been observed), and (2) measurements without bottom effect (WMDs that were at least $20 \mathrm{~m}$ above the bottom). Furthermore, an area light intensity was estimated using the LIMD during the period between 07:00 and 19:00 h for each area and for each sampling period. The estimations were compared using analysis of variance and tested for homogeneity using the Bartlett test. All statistical inferences were based on the $p \leq 0.05$ significance level.

Diurnal curve of sardine vertical migration. The idealised curve of the sardine vertical migrations, as well as the time of their theoretical maximum depth, was estimated using cosine analysis. Specifically, we fitted WMD to a cosine model (Nelson et al. 1979):

$$
\mathrm{WMD}=\mathrm{C}_{0}+C \cdot \cos (\omega t+\mathrm{d}),
$$

where $\omega$ is the angular frequency $(2 \pi / 24) ; t$ is the time of day; $C$ is the maximum deviation of the theoretical curve from the level $C_{0}$; and the acrophase $d$ is the hour of maximum positive deviation from the curve (Kuhn et al. 1986). The acrophase value was used to estimate the time of maximum depth. The curves of the WMD were separately examined in the 2 sub-areas: in the Thermaikos Gulf (where depths $<100$ m predominate) and the Thracian Sea (where depths $>100 \mathrm{~m}$ are common).

\section{RESULTS}

The cross-correlation analysis between WMD and LI (mean light intensity of first the $10 \mathrm{~m}$ in the water column) showed an estimated lag of $1 \mathrm{~h}$ in the Thracian Sea and a zero lag in the Thermaikos Gulf in 1995; no significant correlation between WMD and LI was found in the Thermaikos Gulf in 1996 (Fig. 2). The relationships between WMD and $\mathrm{LI}_{t-1}(t=\mathrm{h})$ were multiplicative (Table $3 \mathrm{~A}$ ). The results of stepwise multiple regression analysis among WMDs used as the dependent variable and $\mathrm{LI}_{t-1}, \mathrm{BD}$ (bottom depth) used as the independent variables, gave low values for the DurbinWatson test (Table 3B). The latter revealed the existence of autocorrelation (Zar 1985) among the values of WMD. The difference between the 2 surveys for the Thermaikos Gulf seems to be due to the timing of sampling. The greatest bottom depths were insonified during daylight in 1995, whereas in 1996 the greatest bottom depths were insonified at twilight and during nighttime. As greater depth was insonified in the Thermaikos Gulf in 1995, during high light intensity, a small influence of light intensity was observed.

The estimated ARIMA model revealed that the values of WMD were autocorrelated with lag $=1 \mathrm{~h}$ (Table 4), e.g. each value of WMD was related to the
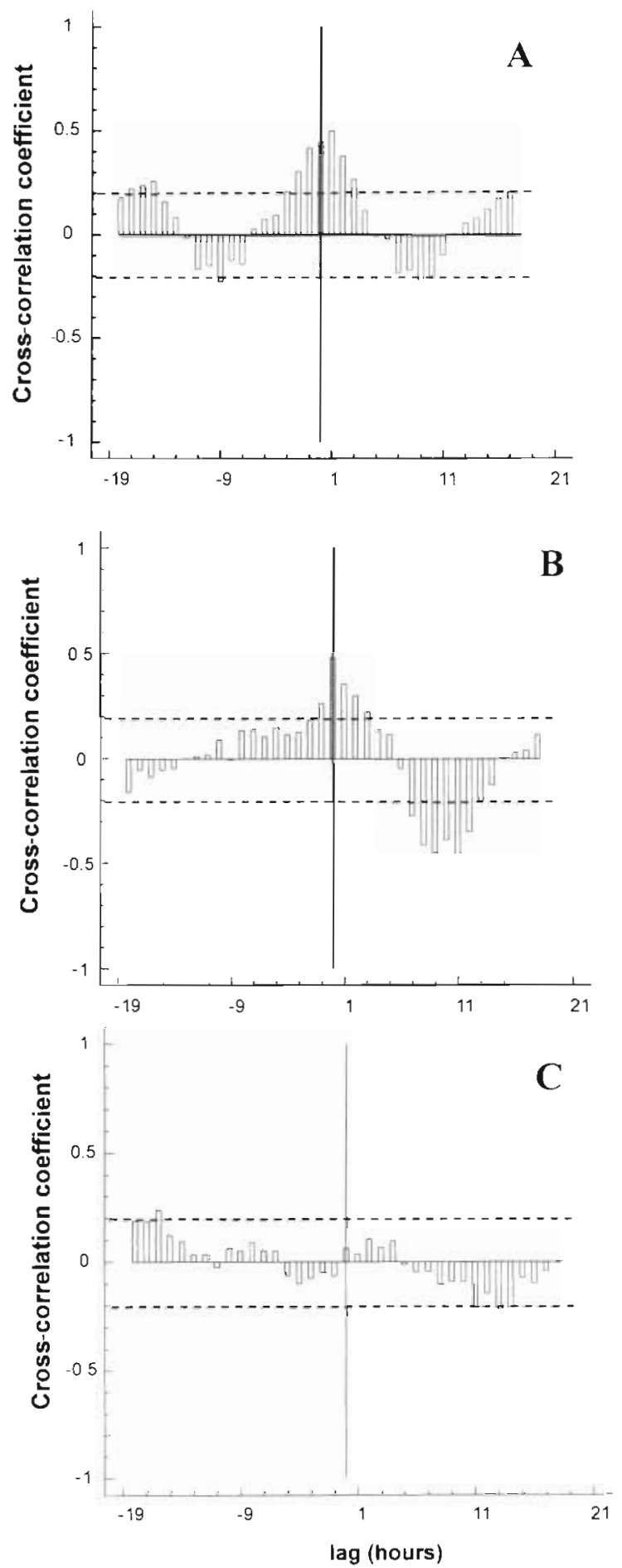

Fig. 2. Sardina pilchardus. Cross-correlation function between weighted mean depth and light intensity in the first $10 \mathrm{~m}$. (A) Thracian Sea; (B) Thermaikas Gulf in 1995; (C) Thermaikos Gulf in 1996. Dashed lines: significance level of correlation $(p<0.05)$. Vertical lines correspond to time lag zero; the left sides correspond to negative time lags (correlation of current values of light with previous values of depth) and the right sides to positive time lags (correlation of current values of light with future values of depth) 
Table 3. Sardina pilchardus. Simple and multiple regression analysis by area and sampling period. WMD: weighted mean depth or the centre of density; LI: mean light density of the first $10 \mathrm{~m}$ in the water column in $\mu \mathrm{E} \mathrm{m}^{-2} \mathrm{~s}^{-1} ; \mathrm{BD}$ : bottom depth in $\mathrm{m}_{i} t:$ time in $h_{i} R^{2}$ : coefficient of determination; $F$ : value of $F$-test. "Significance at the $\mathrm{p}<0.05$ level

\begin{tabular}{|c|c|c|c|c|}
\hline Area & Regression model & $R^{2}$ & $F$ & $\begin{array}{c}\text { Durbin-Watson } \\
\text { test }\end{array}$ \\
\hline \multicolumn{5}{|l|}{ (A) Simple regression } \\
\hline Thracian Sea & $\mathrm{WMD}_{t}=3.64 \times \mathrm{LI}_{t-1}{ }^{0.082}$ & 0.366 & $21.37^{\circ}$ & $0.508^{*}$ \\
\hline Thermaikos Gulf 1995 & $\mathrm{WMD}_{t}=3.64 \times \mathrm{LI}_{t}^{0.056}$ & 0.354 & $17.54^{\bullet}$ & $0.849^{*}$ \\
\hline Thermaikos Gulf 1996 & $\mathrm{WMD}_{t}=3.73 \times \mathrm{LI}_{t}^{-0.0021}$ & 0.070 & 0.04 & $0.845^{\circ}$ \\
\hline \multicolumn{5}{|c|}{ (B) Multiple regression (without autocorrelation factor) } \\
\hline Thracian Sea & $\mathrm{WMD}_{t}=30.93 \times \mathrm{LI}_{t-1}{ }^{0.082}+0.06 \times \mathrm{BD}_{t}$ & 0.523 & $21.30^{\circ}$ & $0.679^{\circ}$ \\
\hline Thermaikos Gulf 1995 & $\mathrm{WMD}_{t}=41.17 \times \mathrm{LL}_{t}^{0.056}+0.11 \times \mathrm{BD}_{t}$ & 0.502 & $17.15^{\circ}$ & $1.055^{\circ}$ \\
\hline Thermaikos Gulf 1996 & $\mathrm{WMD}_{t}=29.47+0.16 \times \mathrm{BD}_{t}$ & 0.230 & $16.27^{\bullet}$ & $1.088^{\circ}$ \\
\hline \multicolumn{5}{|c|}{ (C) Multiple regression (with autocorrelation factor) } \\
\hline Thracian Sea & $\mathrm{WMD}_{t}=13.47 \times \mathrm{LI}_{t-1}{ }^{0082}+0.76 \times \mathrm{WMD}_{t-1}$ & 0.774 & $16.38^{\circ}$ & 1.804 \\
\hline Thermaikos Gulf 1995 & $\mathrm{WMD}_{t}=20.55+0.59 \times \mathrm{WMD}_{t-1}$ & 0.347 & $14.28^{\circ}$ & 2.363 \\
\hline Thermaikos Gulf 1996 & $\mathrm{WMD}_{t}=20.27+0.55 \times \mathrm{WMD}_{t-1}$ & 0.343 & $23.48^{\circ}$ & 2.061 \\
\hline
\end{tabular}

Table 4. Sardina pilchardus. ARIMA models of WMD. $Y=$ WMD in $m_{;} t=$ time in $h_{i} a_{t}=$ is random noise at time $t_{i}$ ARIMA model $=(p$, $d, q$ ), where $p$ is the order of the auto-regressive parameter, $d$ is the difference order and $q$ is the order of the moving average parameters. Estimated standard error $( \pm)$ is shown. 'Significance at the $p<$ 0.05 level

\begin{tabular}{lcc|}
\hline Area & $\begin{array}{c}\text { Adjusted ARIMA } \\
\text { model }(p, d, q)\end{array}$ & ARIMA equation \\
\hline Thracian Sea & $(1,0,0)^{*}$ & $Y_{t}-0.77 \times Y_{t-1}=11.88+\mathrm{a}_{t}$ \\
& & \pm 0.09 \\
Thermaikos Gulf & $(1,0,0)^{*}$ & $Y_{t}-0.63 \times Y_{t-1}=18.10+\mathrm{a}_{t}$ \\
1995 & & \pm 0.16 \\
$\begin{array}{l}\text { Thermaikos Gulf } \\
1996\end{array}$ & $(1,0,0)^{*}$ & $Y_{t}-0.63 \times Y_{t-1}=14.91+\mathrm{a}_{t}$ \\
& & \pm 0.10
\end{tabular}

previous one. The second stepwise multiple regression analysis among WMDs used as the dependent variable and $\mathrm{LI}_{t-1}, \mathrm{BD}$, and $W \mathrm{MD}_{t-1}$ used as the independent variables showed best fit to the data with no autocorrelation among the values of WMD (Durbin-Watson test value $\approx 2$ ). In these relationships the variable $\mathrm{WMD}_{t-1}$ incorporated the bottom depth effect (Table 3C). Furthermore, the results of regression analysis (with autocorrelation factors) revealed that only in the Thracian Sea (deep waters) did light intensity make a significant contribution to the explained variance $(-45 \%)$. The absence of the LI variable from the Thermaikos Gulf models was probably due to the bottom effect. Consequently, only data from the Thracian Sea were used for further analysis.

The WMD in relation to the corresponding ambient light intensity (LIMD) is presented in Fig. 3A. The $\Delta$ LI (hourly changes of light intensity at WMD) remained more or less constant in the first half of the day. In the second half, the $\triangle \mathrm{LI}$ decreased at a constant rate (Fig. 3B). Furthermore, the LIMD was also used to calculate the luminance in the horizontal direction and luminance in the vertically downward direction. According to Whitney (1969) luminance in the horizontal direction and in the vertically downward direction is approximately $1 / 10$ and $1 / 50$ of the vertically upward direction, respectively (Fig. 3C). Since the absorption of light with depth is exponential, small changes in depth resulted in much greater changes in LIMD (the light intensity at the mean depth of sardines). This effect was clearer after 10:00 h (a dip in the light intensity curve) since after this time light intensity in the surface was more stable and the sardines was found deeper in the water column (Fig. 3A).

Analysis of variance between PLI and area light intensity showed that light intensity at the WMD in the Thermaikos Gulf (shallow area) was higher than that in the Thracian Sea (deep area) at a significance level of $p<0.05$. The mean values of LIMD during twilight together with PLI values are presented in Table 5. Our field measurements, for the reforming or breaking up of schools were slightly higher during twilight than the thresholds estimated in the laboratory. Furthermore, a wide range of PLI was estimated (Table 5), implying that sardines probably did not adjust their depth according to the vertically upward luminance, but rather according to the horizontal or the vertically downward (background) luminance (Fig. 3C).

The time of deepest WMD was estimated from cosine analysis to be after midday (approx. 12:37 to 12:45 h) in the Thracian Sea (Fig. 4) and in the Thermaikos Gulf in 1995, whereas no significant cosine relationship to describe the diel sardine depth curve 
was found for the Thermaikos Gulf in 1996 (Table 6). The amplitude of the vertical displacement of the sardines was greater in deeper than in shallower water.

\section{DISCUSSION}

Clupeids undergo diurnal vertical migrations which are triggered by light (Blaxter \& Parrish 1965, Woodhead 1966, Blaxter 1970). As regards vertical migration, particular attention has been given to the behaviour of clupeids because of their wide distribution, their commercial importance and the often well-defined nature of their movements (Woodhead 1966). In terms of vertical migration and behaviour under different experimental light conditions, herring and sardines are the most intensively studied fishes. Nevertheless, field studies of the vertical migrations and the behaviour of these species in relation to light intensity are limited.

The present study revealed that the main factors affecting the vertical migration of sardines in the field were light intensity and bottom depth. Specifically, sardines tended to regulate their position in the water column according to the ambient light intensity when they were not restricted by the sea bed. In this case the fish responded to changes in the surface light intensity with a lag of $1 \mathrm{~h}$. Obviously, the sampling unit (1 h) limited the precision of our lag estimations. Weston \& Andrews (1990), using sonar observation over a period of $5 \mathrm{yr}$, examined the timing of the breaking up and reforming of sardine schools. They found a difference in response at dawn and dusk. Specifically, they found that the sardines' Iesponse lags
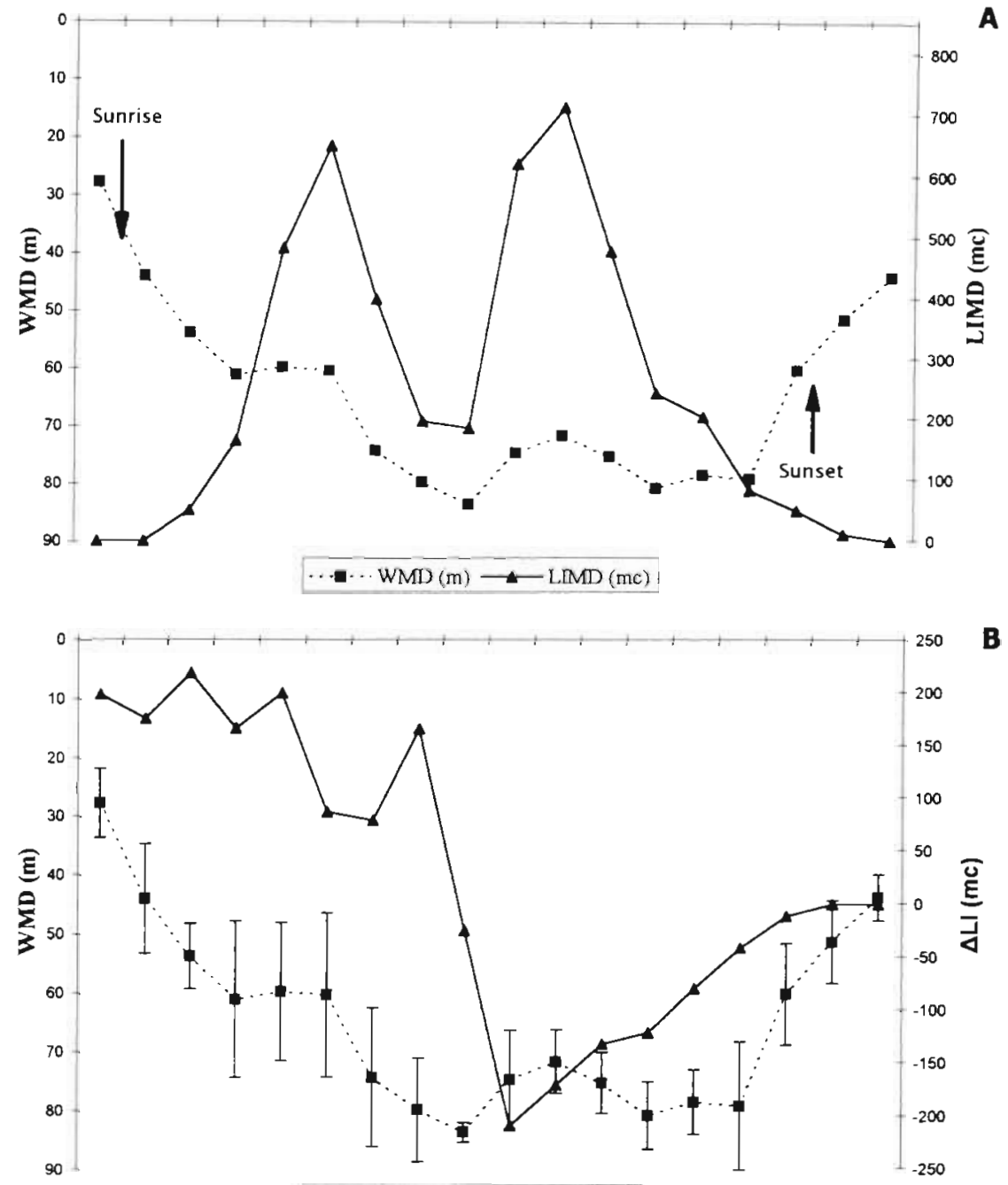

$\cdots W M \bar{D}(m) \rightarrow \Delta \mathrm{LI}(\mathrm{mc})$

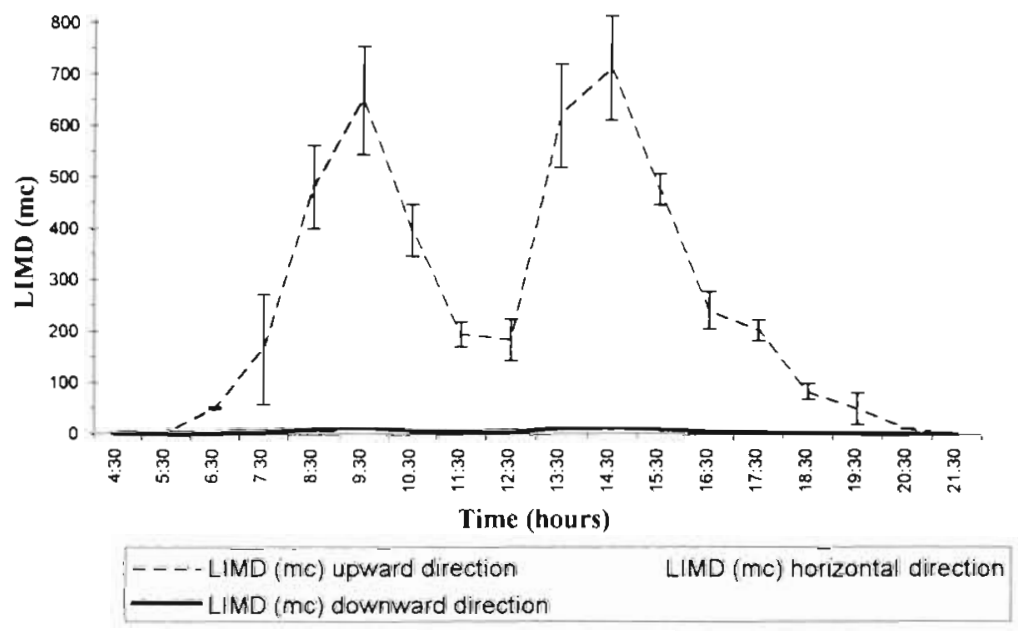

Fig. 3. Sardina pilchardus. (A) WMD and its corresponding light intensity at the WMD (LIMD) in the Thracian Sea. Sunrise and sunset indicated by arrows. (B) WMD in the Thracian Sea with the corresponding hourly changes in ambient light intensity ( $\Delta$ LI). The confidence intervals of the WMD are fitted. Positive values of $\Delta$ LI indicate increase in light intensity during the first part of the day, while negative values indicate decrease in light intensity during the second part of the day. (C) Mean hourly LIMD with confidence intervals of estimation in the Thracian Sea. The LIMD calculated horizontally and vertically downward are also indicated for comparison. Horizontal luminance was calculated as $1 / 10$ of the vertically upward luminance, while the downward luminance was calculated as 1/50 of the upward luminance (Weston \& Andrews 1990) 
Table 5. Sardina pilchardus. Estimated preferred light intensity (PLI), as well as light intensity at the mean depth of sardines (LIMD), with standard error during twilight. PLI in mc estimated for all areas and sampling periods; minimum and maximum PLI values also given. Minimum values given for twilight are an approximation to the light intensity thresholds. Sunrise during the sampling ranged from 05:00 to 05:04 $\mathrm{h}$, and sunset was from 19:45 to $19: 50 \mathrm{~h}$

\begin{tabular}{|lccc|}
\hline Time (h) & $\begin{array}{c}\text { Thracian } \\
\text { Sea }\end{array}$ & $\begin{array}{c}\text { Thermaikos } \\
\text { Gulf } 1995\end{array}$ & $\begin{array}{c}\text { Thermaikos } \\
\text { Gulf } 1996\end{array}$ \\
\hline $\begin{array}{l}\text { LIMD } \\
\text { 04:00-05:00 } \\
\text { Average value } \\
\text { Range }\end{array}$ & $1.43 \pm 0.1$ & $1.50 \pm 0.3$ & $1.31 \pm 0.2$ \\
05:00-06:00 & $1.01-2.40$ & $0.94-1.99$ & $0.93-1.69$ \\
$\quad \begin{array}{l}\text { Average value } \\
\text { Range }\end{array}$ & $1.94 \pm 0.4$ & $5.63 \pm 1.6$ & $16.38 \pm 15.3$ \\
21.00-22.00 & $1.32-2.66$ & $3.31-7.40$ & $1.56-41.31$ \\
$\quad \begin{array}{ccc}\text { Average value } \\
\text { Range }\end{array}$ & $1.26 \pm 0.3$ & $1.68 \pm 0.3$ & $1.04 \pm 1.0$ \\
PLI & $0.94-1.93$ & $1.04-2.01$ & $0.94-1.84$ \\
Average value & \multicolumn{3}{c}{$538.52 \pm 11.6$} \\
Range & $63.8-1510.7$ \\
\hline
\end{tabular}

30 min at dusk and 45 min at dawn behind the respective light intensity values. Consequently, the shoals dispersed quite rapidly, whereas fish spread over an area may need some time to find each other and congregate into a school (Weston \& Andrews 1990). Furthermore, cosine analysis of our data revealed that sardines reached maximum depth 37 to $45 \mathrm{~min}$ after midday (maximum light intensity).

The hourly position of sardines was autocorrelated in the 3 models. When the autocorrelation factor was used in the models, it incorporated the bottom effect. The autoregressive factor expressed the rate of sardine movement in the water column. It is known that sardines move offshore during the daytime and inshore during the night (Skrivanic \& Zavodnik 1973). The relationships we describe confirm this phenomenon. Sardines migrated vertically faster when there was only a small or no bottom effect (Thracian Sea) than when they were moving to deeper water along the bottom slope (Thermaikos Gulf). In conclusion, the models did not differ from each other from an ecological point of view: only the different strength of the factors involved affected sardine movements.

A significant percentage of variance remains unexplained. In addition to bottom depth and light intensity, several other factors determine the depth position of sardines in the water column that have not been taken into account in the present study. Among them the most important are individual fish size (Protasov 1970), the presence of other species and schools (Masse et al. 1996) and the presence of predators (Masse et al.
1996). It appears that the factors that affect sardine position, other than light and bottom depth, tend to decrease the depth of the centre of density (Woodhead 1966).

We used the Thracian Sea measurements for further analysis of sardine movement, as only in the Thracian Sea (deeper water) did LI explain a high percentage $(-45 \%)$ of the total variance (Table $3 \mathrm{C}$ ). The multiplicative relationship between $\mathrm{LI}$ and WMD revealed that the centre of sardine density tended to level out as the corresponding ambient LI increased. The same was observed in the mean hourly WMD (Fig. 3B). We distinguished 3 phases of sardine movements during the daytime: (1) descending at dawn, (2) holding depths and (3) ascending at dusk. The centre of sardine density descended between 04:00 and 07:00 h and ascended between 19:00 and 22:00 h. In between dawn and dusk, sardines remained at about the same depth, with only a small adjustment of their position to the ambient light intensity.

Descending, ascending and holding at depth seem to be regulated by different mechanisms. Specifically, 2 patterns of change in ambient light intensity $(\Delta \mathrm{Ll})$ were observed during the daytime. In the first part of the day there was a rather constant increase in LI. During the last part of the day there was a gradual decrease in ambient LI. Sardine depth increased in the first hours of the day and tended to stabilise when ambient LI had increased from 52 to $166 \mathrm{mc}$. The reverse was observed during ascension, the sardines began to ascend when the ambient light decreased from 84 to $51 \mathrm{mc}$. It seems that a threshold between 84 and $51 \mathrm{mc}$ triggered the end of the abrupt descent and the beginning of the return of the sardines to the sur-

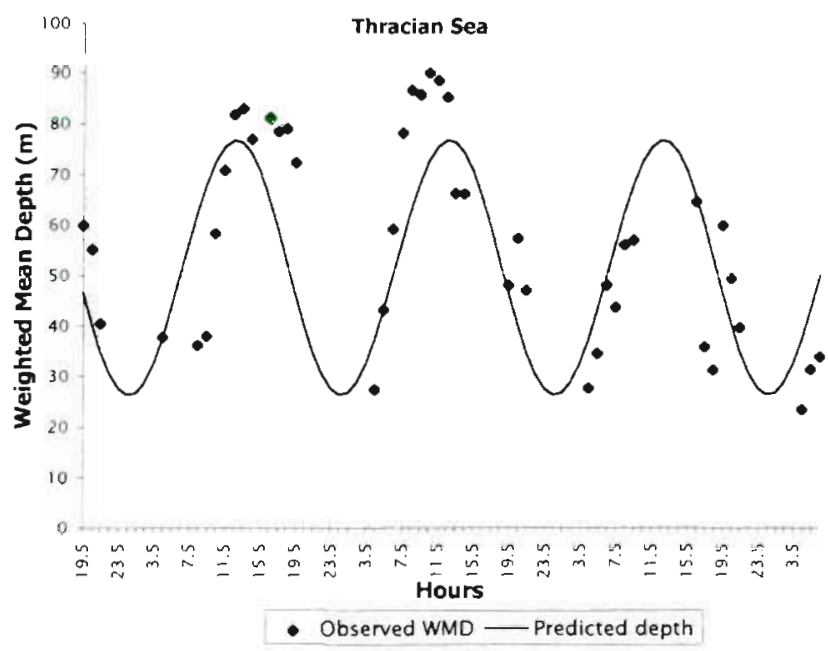

Fig. 4, Sardina pilchardus. WMD values in the Thracian Sea (observed values) and the corresponding cosine curve (predicted values) 
Table 6. Sardina pilchardus. Cosine analysis of WMD in $\mathrm{m} ; t=$ time in $\mathrm{h} ; \mathrm{R}^{2}=$ coefficient of determination; $F=$ value of $F$-test. - Significance at the $p<0.05$ level

\begin{tabular}{|c|c|c|c|}
\hline Area & Cosine model & $R^{2}$ & $F$ \\
\hline Thracian Sea & $\begin{aligned} & W M D= 51.55-25.29 \cos [(2 \pi / 24) t+12.37] \\
& \pm 0.29 \pm 0.54 \\
& 00.102\end{aligned}$ & 0.707 & $28.11^{\circ}$ \\
\hline Thermaikos Gulf 1995 & $\begin{aligned} W M D= & 47.20-7.08 \cos [(2 \pi / 24) t+12.45] \\
& \pm 0.20 \pm 0.34\end{aligned}$ & 0.271 & $10.15^{\circ}$ \\
\hline Thermaikos Gulf 1996 & $\begin{aligned} W M D= & 40.62-1.76 \cos [(2 \pi / 24) t+8.52] \\
& \pm 0.18 \pm 0.35 \quad \pm 2.24\end{aligned}$ & 0.013 & 0.36 \\
\hline
\end{tabular}

face. Muzinic (1964) reported that the sudden change of white light from 10 to $100 \mathrm{mc}$ induced an immediate descesion of sardines under experimental conditions. This value seems to be high for a threshold in the field. We estimated that ambient LI at the depth of the sardines increased at a rate of 100 to $200 \mathrm{mc} \mathrm{h}^{-1}$. Furthermore, this change activated descension only during the first hours of the day, whereas later in the day similar changes did not induce significant changes in sardine depth

There was a wide range of PLI during the daytime. The same has also been reported by Blaxter \& Parrish (1965) for herring. According to their results, although the PLI varied (10 to $1000 \mathrm{mc}$ ), herring showed no consistent tendency to be deeper on bright days or in clearer water. They found no evidence that actual daytime depth of the herring depended on light intensity. Cushing (1960) reported 25 to $100 \mathrm{mc}$ as a 'preferred' range of light intensity for the sardine in the English Channel during summer. These values, which were calculated using surface luminance, were much higher than our estimate. The range estimated by Cushing (1960) corresponds to our minimum measurements and to the PLI in the horizontal plane (Fig. 3C).

It seems that the background luminance is the most important factor for sardine vertical migrations. During the early hours of the day there was a sudden increase in light over the dark background of the sea, which activated negative phototactic behaviour resulting in the fish descending. Subsequently, when the light became diffuse and the background light intensity high, sardines did not change their depth significantly. An equal change in the ambient light intensity resulted in much smaller changes in sardine position compared to those during the first hours of the day. The contrast between fish and ambient light intensity could be a criterion for fish reflugence adjusting their depth. Specifically, fish tend to adjust their depth so as minimise their contrast with the background; that is, minimising the ratio $(F-B) / B$, where $F$ and $B$ are the brightness of the fish and the background respectively (Blaxter 1980). However, what sardines really see and what causes them to regulate their depth is questionable. Probably, in their attempts to match the background space light level they are relying more on horizontal or upwelling light intensity than the downwelling light that we measured (Blaxter \& Parrish 1965, Whitney 1969). If this is so, the PLI will be much lower (Fig. 3C). The relationship between the amount of light required for image perception and ambient luminance is dependent upon the scattering properties of the water and is independent of light intensity, so that, above a critical visual threshold, underwater visibility can be expected to be almost constant over a wide range of intensities (Sokolov 1961).

At dusk the decrease in light activated the reverse effect, i.e. positive phototactic behaviour. Specifically, although light intensity decreased the background became darker) fish ascended only when the ambient light decreased to less than $84 \mathrm{mc}$. During this time interval, the background became darker and the light less diffuse. When the background became dark enough and the sunlight more localised, positive phototaxis was activated and the fish ascended. Their positive phototaxis at dusk was associated with feeding behaviour (Vucetic 1961). Fishing with light at night takes advantage of this behaviour. During the night, sardines tend to concentrate in the vicinity of isolated light sources. Verheijen (1955) noted that this behaviour was not caused by the light itself but by the darkness of the environment. It is well known that the diffuse light from the moon makes fishing with light ineffective.

The field measurements during twilight were always higher than the thresholds estimated in the laboratory. Specifically, all the mean values during twilight at sea were higher than those estimated in the laboratory for the breakup or reformation of sardine schools. Assuming that high light intensity levels restrain feeding (Muzinic 1963, 1964), the sardines began feeding after 21:00 $\mathrm{h}$ in the summer. Possibly, the more frequent the measurements of light intensity, the more accurate the determination of light thresholds in the field will be. Our hourly measurements during twilight did not pro- 
vide the desired precision. Continuous measurement of light intensity is necessary to estimate field thresholds (Blaxter \& Parrish 1965). Field conditions that influence fish behaviour are a great deal more complicated than was once thought, and extensive, largescale studies are required to improve our understanding of fish behaviour in the wild.

Acknowledgements. We thank Prof. K. Koutsikopoulos for his help, Prof. J. Blaxter and Prof. B. Nafpaktitis for their critical reading of an earlier version of this manuscript, and the 4 anonymous reviewers for their valuable comments. We also thank L. Manousakis, A. Kapandagakis and the crew of the RV 'Philia' for their help in collecting data.

\section{LITERATURE CITED}

Arnold GP (1995) Mini-symposium on fish migration. Introduction. ICES J Mar Sci 52:887-888

Batty RS, Blaxter JHS, Richard JM (1990) Light intensity and the feeding behaviour of herring, Clupea harengus. Mar Biol 107:383-388

Blaxter JHS (1964) Spectral sensitivity of the herring Clupea harengus L. J Exp Biol 41:155-162

Blaxter JHS (1966) The effect of light intensity on the feeding ecology of herring. Symp Br Ecol Soc 6:393-409

Blaxter JHS (1970) 2. Fishes, Chap 2.32. In: Kinne O (ed) Marine Ecology, Vol. I, Part I. Wiley Interscience, London p 213-286

Blaxter JHS (1980) Vision and the feeding of fishes. In: Bardach JE, Magnuson JJ, May RC. Reinhart JM (eds) Fish behavior and its use in the capture and culture of fishes. Proceedings of the conference on the physiological and behavioral manipulation of food fish as production and management tools. Int Center for Living and Aquat Resources Management, Manila, p 32-56

Blaxter JHS, Holliday FGT (1958) Factors influencing the feeding behaviour of herring. Proc R Soc Edinburgh 27 : $15-28$

Blaxter JHS, Hunter JR (1982) The biology of the clupeoid fishes. Adv Mar Biol 20:1-223

Blaxter JHS, Parrish BB (1965) The importance of light in shoaling, avoidance of nets and vertical migration by herring. J Cons Perm Int Explor Mer 30(1):40-57

Culley M (1970) The Pilchard. Biology and exploitation. Pergamon Press, New York

Cushing $\mathrm{DH}$ (1960) Fishing gear and fish behaviour. Proc World Sci Meet Biol Sardines Related Species 3:1307-1326

Gutierrez E, Morales-Nin B (1986) Time series analysis of daily growth in Dicentrarchus labrax L. otoliths. J Exp Mar Biol Ecol 103:163-179

Heath MR, Henderson EW, Baird DL (1988) Vertical distribu-

Editorial responsibility: Otto Kinne (Editor),

Oldendorf/Luhe, Germany tion of herring larvae in relation to physical mixing and illumination. Mar Ecol Prog Ser 47:211-228

Kmenta J (1986) Elements of econometrics. Macmillan Publish Company, New York

Kuhn ER, Corneillie S, Ollevier F (1986) Circadian variation in plasma osmolarity, electrolytes, glucose and cortisol in carp (Cyprinus carpio). Gen Comp Endocrinol 61:459-468

MacLennan DN, Simmonds EJ (1992) Fisheries acoustics Chapman and Hall, London

Masse J, Koutsikopoulos C, Patty W (1996) The structure and spatial distribution of pelagic fish schools in multispecies clusters: an acoustic study. J Mar Sci 53(2):155-160

Muzinic R (1963) Further observations on schooling and aggregating behaviour of sardines (Sardina pilchardus Walb.) Proc Gen Fish Coun Medit 7:319-323

Muzinic R (1964) Some observations on the reactions of the sardine (Sardina pilchardus Walb.) to light under experimental conditions. Acta Adriat 11(30):219-226

Nelson W, Liang Tong Y, Lee JK, Halberg F (1979) Methods for cosino-rhythmometry. Chronobiologia 6:305-323

Protasov VR (1970) Vision and near orientation of fish. Translated from Russian, Israel Program for Scientific Translations, Jerusalem

Skrivanic A, Zavodnic D (1973) Migrations of the sardine (Sardina pilchardus) in relations to hydrographical conditions of the Adriatic sea. Neth J Sea Res 7:7-18

Sokolov OA (1961) Visual underwater observations at the 5th cruise of the submarine 'Seberianka.' Oceanologia 4: $757-761$

Stergiou K (1989) Modelling and forecasting the fishery for pilchard (Sardina pilchardus) in Greek waters using ARIMA time-series models. J Cons Int Explor Mer 46:16-23

Tsimenides N, Bazigos G, Georgakarakos E, Kapandagakis A (1995) Distribution of acoustic pelagic fish populations in the northern Aegean Sea. Proc World Fish Cong 5:33-42

Verheijen FJ (1955) On a method for collecting and keeping clupeoids for experimental purposes, together with some remarks on fishery with light-sources and a short description of free cupulae of the lateral line organ on the trunk of the sardine Clupea pilchardus. Pubbl Stn Zool Napoli 28: $225-240$

Vucetic T (1961) Feeding habits of the adult sardine (Sardina pilchardus Walb.) Proc Gen Fish Counc Medit Tech Paper 40:361-364

Weston DE, Andrews HW (1990) Seasonal sonar observation of the diurnal shoaling times of fish. J Acoust Soc Am $87(2): 673-680$

Whitney RR (1969) Schooling of fished relative to available light. Trans Am Fish Soc 3:497-504

Wonnacott TH, Wonnacott RJ (1981) Regression: a second course in statistics. John Wiley and Sons, New York

Woodhead PMJ (1966) The behaviour of fish in relation to light in the sea. Oceanogr Mar Biol Annu Rev 4:337-403

Zar JH (1985) Biostatistical analysis. Prentice Hall, Inc, New Jersey

Submitted: December 10, 1997; Accepted: November 18, 1998 Proofs received from author(s): March 1, 1999 